\title{
Activation of activin/Smad 2 and 3 signaling pathway and the potential involvement of endothelial-mesenchymal transition in the valvular damage due to rheumatic heart disease
}

\author{
SHENGLIN XIAN ${ }^{1,2}$, ANG CHEN $^{1,2}$, XIAODAN WU ${ }^{1,2}$, CHUANGHONG LU $^{1,2}$, \\ YUNJIAO WU ${ }^{1,2}$, FENG HUANG ${ }^{1,2}$ and ZHIYU ZENG ${ }^{1,2}$

\begin{abstract}
${ }^{1}$ Department of Cardiology, The First Affiliated Hospital of Guangxi Medical University; ${ }^{2}$ Guangxi Key Laboratory Base of Precision Medicine in Cardio-cerebrovascular Diseases Control and Prevention and Guangxi Clinical Research Center for Cardio-cerebrovascular Diseases, Guangxi Medical University, Nanning, Guangxi 530021, P.R. China
\end{abstract}

Received March 6, 2020; Accepted October 13, 2020

DOI: $10.3892 / \mathrm{mmr} .2020 .11648$

\begin{abstract}
Rheumatic heart disease (RHD) is an autoimmune disease caused by rheumatic fever following group A hemolytic streptococcal infection and primarily affects the mitral valve. RHD is currently a major global health problem. However, the exact pathological mechanisms associated with RHD-induced cardiac valve damage remain to be elucidated. The endothelial-mesenchymal transition (EndMT) serves a key role in a number of diseases with an important role in cardiac fibrosis and the activin/Smad 2 and 3 signaling pathway is involved in regulating the EndMT. Nevertheless, there are no studies to date, to the best of the authors' knowledge, investigating the association between RHD and EndMT. Thus, the aim of the current study was to investigate the potential role of EndMT in cardiac valve damage and assess whether activin/Smad2 and 3 signaling was activated during RHD-induced valvular injury in a rat model of RHD induced by inactivated Group A streptococci and complete Freund's adjuvant. Inflammation and fibrosis were assessed by hematoxylin and eosin and Sirius red staining. Serum cytokine and rheumatoid factor levels were measured using ELISA kits. Expression levels of activin/Smad 2 and 3 signaling pathway-related factors [activin A, Smad2, Smad3, phosphorylated (p-)Smad2 and p-Smad3], EndMT-related factors [lymphoid enhancer factor-1 (LEF-1), Snail1, TWIST, zinc finger E-box-binding homeobox (ZEB)1, ZEB2, $\alpha$ smooth muscle actin ( $\alpha$-SMA) and type I collagen $\alpha 1$ (COL1A1)], apoptosis-related markers (BAX and cleaved caspase-3) and valvular inflammation markers
\end{abstract}

Correspondence to: Professor Zhiyu Zeng, Department of Cardiology, The First Affiliated Hospital of Guangxi Medical University, 6 Shuangyong Road, Nanning, Guangxi 530021, P.R. China

E-mail: drzyzeng@126.com

Key words: rheumatic heart disease, endothelial-mesenchymal transition, activin, Smad2, Smad3, valvular damage
$(\mathrm{NF}-\kappa \mathrm{B}$ and $\mathrm{p}-\mathrm{NF}-\kappa \mathrm{B})$ were detected using reverse transcription-quantitative PCR and western blot analyses. Compared with the control group, the degree of valvular inflammation and fibrosis, serum levels of IL-6, IL-17, TNF- $\alpha$ and expression of apoptosis-related markers (BAX and cleaved caspase-3) and valvular inflammation marker ( $\mathrm{p}-\mathrm{NF}-\kappa \mathrm{B})$, activin/Smad2 and 3 signaling pathway-related factors (activin A, p-Smad2 and p-Smad3), EndMT-related factors (LEF-1, Snail1, TWIST, ZEB 1, ZEB2, $\alpha$-SMA and COL1A1) were significantly increased in the RHD group. These results suggested that the activin/Smad 2 and 3 signaling pathway was activated during the development of valvular damage caused by RHD and that the EndMT is involved in RHD-induced cardiac valve damage.

\section{Introduction}

Rheumatic heart disease (RHD) is an autoimmune disease caused by rheumatic fever following group A hemolytic streptococcal infection (1). RHD remains a major global health problem and although primary (the use of antibiotics for people suffering from acute streptococcal pharyngitis to reduce the occurrence of rheumatic fever) and secondary prevention (the use of antibiotic prophylactic measures for people with a history of rheumatic fever or RHD to reduce the recurrence of rheumatic fever) strategies have been clearly defined (2), but their global implementation is not perfect (3). Moreover, the exact pathological mechanism of RHD-induced cardiac valve damage remains unclear. RHD causes $\sim 300,000$ mortalities worldwide every year $(4,5)$ and the effective treatment at present is surgery (6). While valve surgery is expensive, has high technical requirements and requires long-term medication afterwards (3), severely limiting the quality of life of the patients. Therefore, it is important to study the pathogenic mechanism and identify new therapeutic targets for RHD. To this end, the present study investigated the most common RHD, identified as mitral valve disease following review of the results of previous histopathological analyses (7). This finding led to the question: By which process is mitral valve disease directly associated? The mitral valve is formed by two layers of endothelial cells that tightly cover connective tissue (3). 
When diseased, endothelial cells form lesions, which involves connective tissue, leading to scarring and causing permanent damage and chronic disease $(8,9)$. Thus, valvular disease is directly associated with endothelial damage.

The endothelial-mesenchymal transition (EndMT) is associated with endothelial damage and is a process by which endothelial cells lose the endothelial phenotype and acquire the characteristic phenotype of mesenchymal cells. In the heart, the process of EndMT and activation of related signaling pathways are primarily associated with cardiac development and a variety of diseases processes (10). For example, Wei et al (11) showed that the EndMT serves an important role in cardiac fibrosis and that inhibiting EndMT-related signaling pathways slows the progression of heart disease caused by cardiac fibrosis. Furthermore, Xiao et al (12) demonstrated that the TGF- $\beta 1 /$ Smad signaling pathway is involved in the RHD-mediated atrial fibrosis. Smads are also key EndMT factors, as the phosphorylation of Smad 2 and 3 regulates EndMT-related transcription factors to induce the EndMT process $(13,14)$, which also suggests that the EndMT may be involved in RHD.

The EndMT is regulated by the TGF- $\beta$ signaling pathway and important factors in this regulatory process include activin and Smad2 and 3 (15). Activin, which is a member of the TGF- $\beta$ subfamily, has the same expression pattern as TGF- $\beta$ during TGF- $\beta$-induced signal transduction (16). Activin forms complexes with related receptors (activin receptor I and II) on the cell membrane and following phosphorylation it forms docking sites that bind to the transcription factors Smad2 and Smad3 $(17,18)$. The Smad2/3 complex is phosphorylated at Ser residues in the $\mathrm{C}$-terminal domain, inducing transcription of key genes that are associated with the EndMT. EndMT-related transcription factors that are directly regulated by the $S m a d 2 / 3$ complex include lymphoid enhancer factor- 1 (LEF-1), Snail1, TWIST, zinc finger E-box-binding homeobox (ZEB)1 and ZEB2 $(13,14,16,19-21)$. To date, there have been no studies investigating the association between RHD and the EndMT to the best of the authors' knowledge.

In summary, RHD is associated with endothelial damage, endothelial damage is associated with EndMT and EndMT is regulated by the activin/Smad2 and 3 signaling pathway. Therefore, it was hypothesized that activin/Smad2 and 3 signaling is activated during the development RHD-mediated valvular damage and that the EndMT may be involved in RHD-induced cardiac valve damage.

The present study established an RHD rat model to assess whether the activin/Smad 2 and 3 signaling pathway is activated during the development of RHD-induced cardiac valve damage by evaluating differences in expression of activin/Smad2 and 3 signaling pathway-related factors [activin A, Smad2, Smad3, phosphorylated (p-)Smad2 and p-Smad3] between RHD model rats and normal rats. The present study also assessed whether the EndMT is involved in RHD-induced cardiac valve damage by evaluating whether there were differences in expression of EndMT-related factors that are directly regulated by the activin/Smad 2 and 3 signaling pathway (LEF-1, Snail1, TWIST, ZEB1 and ZEB2) and mesenchymal markers $[\alpha$ smooth muscle actin ( $\alpha$-SMA) and type I collagen $\alpha 1$ (COL1A1)] $(22,23)$ between RHD model rats and normal rats. The results of the present study may improve our understanding of the potential association between EndMT and RHD as well as provide new ideas for exploring the pathogenesis and therapeutic targets of RHD.

\section{Materials and methods}

Antigen preparation. Group A streptococci (GAS, cat. no. ATCC19615; American Type Culture Collection) were cultured in brain heart infusion medium (Guangdong Huankai Microbial Sci. \& Tech. Co., Ltd.) at $37^{\circ} \mathrm{C}$ for $24 \mathrm{~h}$ and then washed with normal saline (NS). Following harvesting, the GAS were inactivated by incubating in $10 \%$ neutral formalin for $12 \mathrm{~h}$. Subsequently, the inactivated GAS were washed in NS, resuspended in NS and the density was adjusted to $4.0 \times 10^{11} \mathrm{CFU} / \mathrm{ml}$. Finally, the suspensions were emulsified by sonication (Sonics \& Materials, Inc.) and the antigen was prepared. Each sonication treatment lasted $2 \mathrm{sec}$, with a $2.5 \mathrm{sec}$ interval between each treatment. The entire sonication treatment was performed at $10^{\circ} \mathrm{C}$ and lasted $10 \mathrm{~min}$, and the frequency of ultrasound was $20 \mathrm{kHz}$.

Animals and groups. A total of 16 healthy 8 -week-old adult female Lewis rats (160-180 g) were purchased from Beijing Vital River Animal Technology Co., Ltd. Rats were acclimatized for 5 days. The rats were housed in a specific pathogen-free animal laboratory at the Center of Animal Experiments of Guangxi Medical University at $23 \pm 2^{\circ} \mathrm{C}$ with a 12-h light/dark cycle and were allowed unrestricted cage activity and unlimited access to water and standard chow. All animal experimental procedures performed in this study were performed in accordance with the ethical guidelines for the care and use of experimental animals and were approved by The Medical Ethics Committee of the First Affiliated Hospital of Guangxi Medical University (Nanning, China; approval no. 2019-KY-E-053). All rats were randomly divided into two groups: i) The control group $(n=8)$; and ii) the RHD group $(n=8)$. All rats were maintained on soft bedding and not in wire-bottomed cages, as footpad injection with complete Freund's adjuvant (CFA; Sigma-Aldrich, Merck KGaA) was essential for establishing the RHD rat model. A total of 9 weeks were required to establish the RHD rat model. First, $100 \mu \mathrm{l}$ of a solution comprising inactivated GAS $\left(4.0 \times 10^{11} \mathrm{CFU} / \mathrm{ml}\right)$ and CFA at a 1:1 (v/v) ratio was injected into one hindfoot pad of the rat. Subsequently, 1 week later, $500 \mu 1$ of the same solution was subcutaneously injected subcutaneously into the abdomen at the same interval once a week for 4 weeks. For the last 4 weeks, subcutaneous abdominal injections were performed at the same intervals once a week, but the injection was adjusted to $500 \mu \mathrm{l}$ of inactivated GAS $\left(4.0 \times 10^{11} \mathrm{CFU} / \mathrm{ml}\right)$. Prior to subcutaneous injection, the rats were intraperitoneally anesthetized with ketamine and xylazine at $10 \mathrm{mg}$ and $0.2 \mathrm{mg}$ per $250 \mathrm{~g}$ of body weight, respectively (24-26). Rats in the control group were injected using the same protocol as that described for the RHD group, but the injected solution was an equivalent volume of NS.

Animal sacrifice. Following all treatments, $1 \mathrm{ml}$ of blood was collected from the tail vein of each rat without anesthesia, following which all rats were sacrificed with an intraperitoneal injection of sodium pentobarbital $(150 \mathrm{mg} / \mathrm{kg})$. Mortality was 
determined when $>5$ min passed without evidence of breathing or heartbeat. A body weight loss of $>15 \%$ with a decreased ability to consume food and water was used as the humane endpoint.

Sample preparation. Once rats had been sacrificed, a sample of the heart valve was rapidly collected using surgical instruments then quickly frozen in liquid nitrogen and stored at $-80^{\circ} \mathrm{C}$ for following experiments. All samples were strictly stored in a refrigerator at $-80^{\circ} \mathrm{C}$ and were not removed until performing the experiments to reduce the effect of temperature changes on the samples.

Histochemistry. The samples collected from valves in each group were fixed with $4 \%$ paraformaldehyde at $4^{\circ} \mathrm{C}$ for $24 \mathrm{~h}$ and then dehydrated by 70, 80, 90 and 95\% alcohol and anhydrous alcohol in sequence. After that, the samples were immersed in xylene to replace the alcohol, then placed in the paraffin wax that has been melted in the incubator $\left(58-60^{\circ} \mathrm{C}\right)$ to replace the xylene. Finally, the samples were placed in melted paraffin. After the melted paraffin was solidified, the samples were embedded in paraffin. To perform hematoxylin and eosin (H\&E) staining and Sirius red staining, 5- $\mu \mathrm{m}$-thick serial sections of each block were prepared. For H\&E staining, the sections were stained with $\mathrm{H}$ at room temperature for 4-10 min followed by $\mathrm{E}$ for $0.5-2 \mathrm{~min}$ at room temperature. Subsequently, a BX43 light microscope (Olympus Corporation) was used to capture images of each sample. For Sirius red staining, sections were stained with a Sirius red solution at room temperature for $1 \mathrm{~h}$ before being imaged with a BX43 confocal microscope (magnification, 100x; Olympus Corporation). Then ImageJ (version 1.51j; National Institutes of Health) was used to calculate the area of the valve in the images of H\&E staining and the number of inflammatory cells on the valve area was calculated. The ratio of the number of inflammatory cells to the area of the valve was defined as inflammatory cell density to quantify the H\&E staining results.

Reverse transcription-quantitative $(R T-q) P C R$. Total RNA was extracted from the valve tissues using TRIzol ${ }^{\circledR}$ reagent (Invitrogen; Thermo Fisher Scientific, Inc.) according to the manufacturer's protocol. The RNA concentration was measured using a NanoDrop ${ }^{\mathrm{TM}} 2000$ spectrophotometer (NanoDrop Technologies; Thermo Fisher Scientific, Inc.) and $0.5 \mu \mathrm{g}$ of total RNA was then reverse transcribed into cDNA using a PrimeScript RT reagent kit (Takara Bio, Inc.) according to the manufacturer's protocol (incubation at $37^{\circ} \mathrm{C}$ for $15 \mathrm{~min}$ followed by $85^{\circ} \mathrm{C}$ for $5 \mathrm{sec}$ ). Finally, qPCR was performed using a TB Green Premix Ex Taq II (Takara Bio, Inc.) with a StepOne system (Applied Biosystems; Thermo Fisher Scientific, Inc.) under the following thermal cycling conditions: $95^{\circ} \mathrm{C}$ for $30 \mathrm{~min}$, followed by 40 cycles of $95^{\circ} \mathrm{C}$ for $5 \mathrm{sec}$ and $60^{\circ} \mathrm{C}$ for $30 \mathrm{sec}$. The primer sequences used in the present study are listed in Table I and $\beta$-actin was used as an internal control. The relative changes in mRNA levels were determined as the fold difference relative to $\beta$-actin for each gene using the $2^{-\Delta \Delta \mathrm{Cq}}$ method (27).

Western blot analysis. Total protein was extracted by treating the valve tissues with RIPA lysis buffer (Sangon Biotech Co.,
Table I. Sequences of primers used in reverse transcriptionquantitative PCR.

Gene Primer sequence, 5'-3'

Activin A Forward: TTGCTTGTGAACAGTGCCAGGAG Reverse: TCCCGTCTCCATCCACCTCTTTC

Smad2 Forward: TGTCGTCCATCTTGCCATTCACTC Reverse: TGTTCTCCACCACCTGCTCCTC

Smad3 Forward:CTTCACAGCCGTCCATGACAGTAG Reverse: CCAATGTAGTAGAGCCGCACACC

LEF-1 Forward: CCGAAGAGGAGGGCGACTTA Reverse: TGGGATGATTTCGGACTCGTT

Snail1 Forward: TTCTCTTCCACCTCGGCCTCATC Reverse: GGCTTCGGATGTGCATCTTCAGAG

TWIST Forward: CGACGACAGCCTGAGCAACAG Reverse: GCCGACTGCTGCGTCTCTTG

ZEB1 Forward: AGCCACCGAGAAGCCAGAGTC Reverse: CCAGCGGCAGGTTCACAGAATC

ZEB2 Forward: GAGATAAGGGAGAGCGTTGTG Reverse: AATTGTGGTCTGGATCGTGG

a-SMA Forward: GCGTGGCTATTCCTTCGTGACTAC Reverse: CCATCAGGCAGTTCGTAGCTCTTC

COL1A1 Forward: TGTTGGTCCTGCTGGCAAGAATG Reverse: GTCACCTTGTTCGCCTGTCTCAC

COL3A1 Forward: ACTTCTGGTCCTCCTGGTCTGC Reverse: CGCCTGGCTCACCCTTTTCAC

FSP1 Forward: TGGGGAGAAGGACAGACGAAGC Reverse: TGGCAATGCAGGACAGGAAGAC

$\beta$-actin Forward: GGAGATTACTGCCCTGGCTCCTA Reverse: GACTCATCGTACTCCTGCTTGCTG

BAX Forward: GATGCGTCCACCAAGAAGC Reverse: CCAGTTGAAGTTGCCGTCAG

LEF-1, lymphoid enhancer factor-1; ZEB, zinc finger E-box binding homeobox; $\alpha$-SMA, $\alpha$ smooth muscle actin; COL1A1, type I collagen $\alpha 1$; COL3A1, collagen type III $\alpha 1$; FSP1, fibroblast-specific protein 1 .

Ltd.) according to the manufacturer's protocol and the protein concentration was measured using a bicinchoninic acid protein assay kit (Sangon Biotech Co., Ltd.). Equal amounts of protein $(30 \mu \mathrm{g})$ from each sample were loaded per lane, separated using 10\% SDS-PAGE at $80 \mathrm{~V}$ for $30 \mathrm{~min}$ and $120 \mathrm{~V}$ for 60 min using a blotting system (Bio-Rad Laboratories, Inc.) and then electrotransferred to $0.22-\mu \mathrm{m}$ polyvinylidene fluoride membranes (EMD Millipore) at a constant $80 \mathrm{~V}$ for 80 min. Subsequently, the membranes were blocked with 3\% BSA blocking solution (Sangon Biotech Co., Ltd.) for $1 \mathrm{~h}$ at room temperature and then incubated for $12 \mathrm{~h}$ at $4^{\circ} \mathrm{C}$ with antibodies against the following proteins: Activin A (1:1,000; cat. no. ab128958; Abcam), Smad2 (1:1,000; cat. no. 5339; Cell Signaling Technology, Inc.), Smad3 (1:1,000; cat. no. 9523; Cell Signaling Technology, Inc.), p-Smad2 (1:1,000; cat. no. ab53100; Abcam), p-Smad3 (1:2,000; cat. no. 9145; Cell Signaling Technology, Inc.), LEF-1 (1:1,000; 
cat. no. ab137872; Abcam), Snail1 (1:500; cat. no. 13099-1-AP; ProteinTech Group, Inc.), TWIST (1:500; cat. no. 25465-1-AP; ProteinTech Group, Inc.), ZEB1 (1:500; cat. no. 21544-1-AP; ProteinTech Group, Inc.), ZEB2 (1:1,000; cat. no. ab138222; Abcam), $\alpha$-SMA (1:3,000; cat. no. ab32575; Abcam), COL1A1 (1:3,000; cat. no. ab34710; Abcam) and $\beta$-actin (1:3,000; cat. no. 10068-1-AP; ProteinTech Group, Inc.). Levels of NF- $\kappa \mathrm{B}$ (1:2,000; cat. no. ab16502; Abcam) and p-NF- $\mathrm{BB}(1: 5,000$; cat. no. ab86299; Abcam) as valvular inflammation markers (28) were also examined. As apoptosis serves a key role in the valvular damage (29), levels of the apoptosis-related markers caspase-3 (1:1,000; cat. no. 9662; Cell Signaling Technology, Inc.) and cleaved caspase-3 (1:1,000; cat. no. 9664; Cell Signaling Technology, Inc.) were also detected (30). Following three washes in tris-buffered saline with Tween-20, the membranes were incubated in the dark for $1 \mathrm{~h}$ at room temperature with an HRP-conjugated secondary antibody (1:10,000; cat. no. ab6721; Abcam). A chemiluminescence imaging system (Alpha FluorChem FC3; Alpha, Inc.) was used to visualize the protein bands and ImageJ was used to quantify the expression levels of activin A, Smad2, Smad3, p-Smad2, p-Smad3, LEF-1, Snail1, TWIST, ZEB1, ZEB2, $\alpha$-SMA and COL1A1, which were normalized to $\beta$-actin.

ELISA. ELISA kits (cat. nos. E04640r, E07451r, E11987r and E13666r; Cusabio Technology LLC) were used to measure the serum concentrations of rat IL-6, IL-17, TNF- $\alpha$ and rheumatoid factor (RF) according to the manufacturer's protocols. After preparing all reagents, working standards, samples (serum) and the assay plate, $100 \mu \mathrm{l}$ of standard solution and sample was added to each well, the assay plate covered with the adhesive strip and then the plate was incubated for $2 \mathrm{~h}$ at $37^{\circ} \mathrm{C}$. After removing the liquid in each well, $100 \mu \mathrm{l}$ of biotin-antibody (1X) was added to each well, following which the assay plate was covered with a new adhesive strip and incubated for $1 \mathrm{~h}$ at $37^{\circ} \mathrm{C}$. Subsequently, following removing the liquid by aspiration, each well was washed with wash buffer (provided by the ELISA kit) three times before the addition of $100 \mu \mathrm{l}$ of HRP-avidin (1X) to each well and the assay plate was then covered with a new adhesive strip and incubated for $1 \mathrm{~h}$ at $37^{\circ} \mathrm{C}$. After the aspiration/washing process aforementioned was performed five times, $90 \mu \mathrm{l}$ of TMB substrate was added to each well and the plate was incubated at $37^{\circ} \mathrm{C}$ for $15-30 \mathrm{~min}$ away from the light. Subsequently, after adding $50 \mu \mathrm{l}$ of stop solution to each well and gently tapping the plate to ensure adequate mixing, the absorbance of each well at $450 \mathrm{~nm}$ was measured using a microplate reader (Varioskan LUX; Thermo Fisher, Inc.).

Statistical analysis. All data are presented as the means \pm standard deviation of three independent experiments, unless otherwise shown. Differences between two groups were analyzed using unpaired Student's t-tests. Statistical analyses were performed using SPSS 16.0 (SPSS, Inc.) and $\mathrm{P}<0.05$ was considered to indicate a statistically significant difference.

\section{Results}

Histochemistry. In the H\&E staining experiment, $\mathrm{H}$ stained the cell nucleus a vivid blue and E stained the cytoplasm pink.
Inflammatory cells have a large nucleus and a high ratio of nucleus-to-cytoplasm (31). Therefore, following H\&E staining, inflammatory cells appear blue because of the higher ratio of nucleus-to-cytoplasm, while other cells appear pink because of the lower ratio of nucleus-to-cytoplasm (32). H\&E staining results, as assessed by microscopy, showed myocarditis or valvulitis in the valves of rats in the RHD group, which was not observed in the control group (Fig. 1A). In this experiment, the inflammatory cell density was used as a quantitative indicator of H\&E staining results, which showed that the inflammatory cell density of the valves in RHD group was significantly higher compared with the control group ( $\mathrm{P}<0.05$; Fig. 1C).

Sirius red staining was used to distinguish the types of collagen fibers. A previous study showed that type 1 collagen (COL1) fibers are the primary type of collagen in non-fibrotic valves (33). As the ratio of type 3 collagen (COL3) fibers gradually increases with the progression of fibrosis, a significant increase in the COL3/COL1 (COL3/1) ratio can be used to confirm the onset of valve and myocardial fibrosis. Following Sirius red staining, COL1 fibers appeared as closely packed yellow and red fibers, with obvious birefringence, while COL3 fibers appeared as loosely arranged green fibers, with weak birefringence. The results showed that the COL3/1 ratio in the valves from rats in the RHD group were significantly increased compared with that observed in the control group $(\mathrm{P}<0.05$; Fig. 1B and D).

$R T-q P C R$. mRNA expression of activin/Smad 2 and 3 signaling pathway-related factors (activin A) in the RHD group was significantly increased $(\mathrm{P}<0.05)$ compared with that observed in the control group, while no differences in the mRNA levels of Smad2 and Smad3 were observed between these groups (Fig. 2A). In addition, mRNA expression of EndMT-related factors (LEF-1, Snail1, TWIST, ZEB1, ZEB2, $\alpha$-SMA and COL1A1) in the RHD group was significantly increased (all $\mathrm{P}<0.05$ ) compared with that observed the control group (Fig. 2B and C). mRNA expression of collagen type III $\alpha 1$ chain (COL3A1) and fibroblast-specific protein 1 (FSP1) as fibrosis molecular markers (27) and BAX as apoptosis molecular marker (30) was also examined, the levels of which were significantly increased in the RHD group compared with that observed in the control group $(\mathrm{P}<0.05$; Fig. 2D and $\mathrm{E})$.

Western blot analysis. Protein expression of activin/Smad2 and 3 signaling pathway-related factors (activin A, p-Smad2 and p-Smad3) in the RHD group was significantly increased (all $\mathrm{P}<0.05)$ compared with the control group, with no differences observed in the protein expression of Smad2 and Smad3 between these groups (Fig. 3). Protein expression of EndMT-related factors (LEF-1, Snail1, TWIST, ZEB1, ZEB2, $\alpha$-SMA and COL1A1) in the RHD group was significantly increased (all $\mathrm{P}<0.05$ ) compared with that in the control group (Fig. 4). In addition, protein expression of cleaved caspase-3 and the ratio of $\mathrm{p}-\mathrm{NF}-\kappa \mathrm{B} /$ total $\mathrm{NF}-\kappa \mathrm{B}$ in the RHD group was significantly increased (all $\mathrm{P}<0.05$ ) compared with that in the control group (Fig. 5A-C).

ELISA. Levels of IL-6, IL-17, TNF- $\alpha$ and RF in the RHD group were significantly increased compared with those observed in the control group $(\mathrm{P}<0.05$; Fig. 5D). 


\section{A}

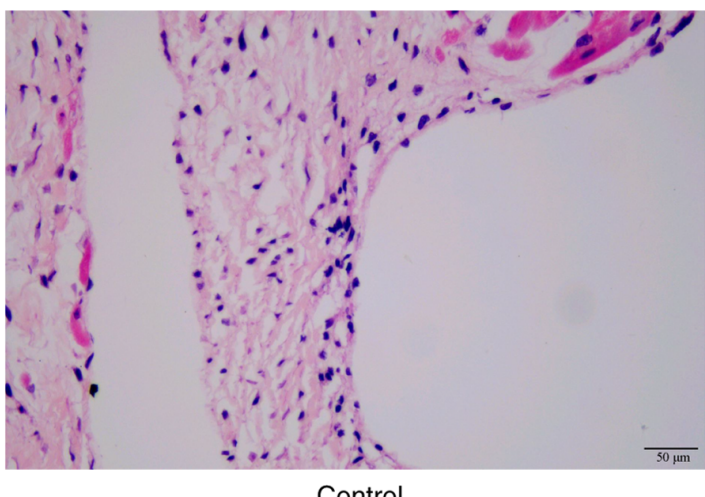

Control

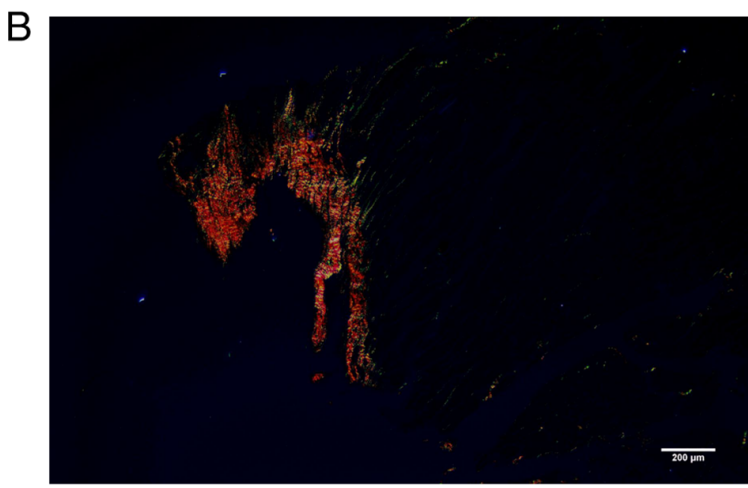

Control

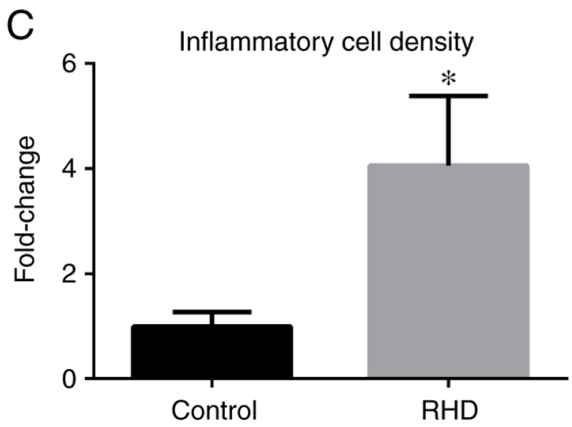

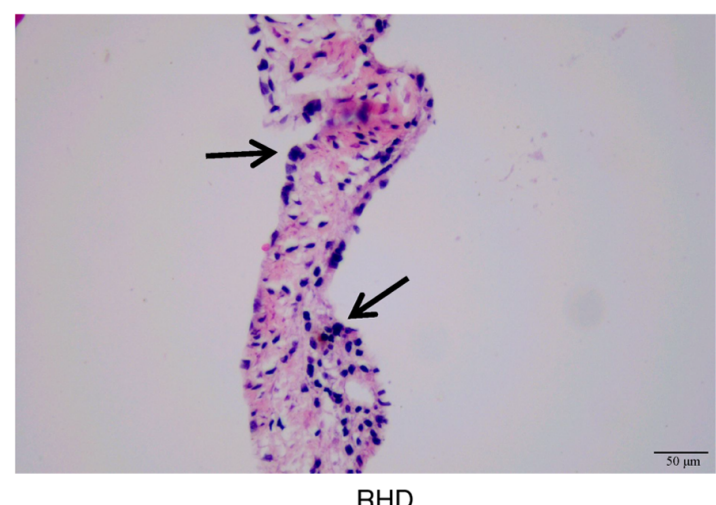

RHD

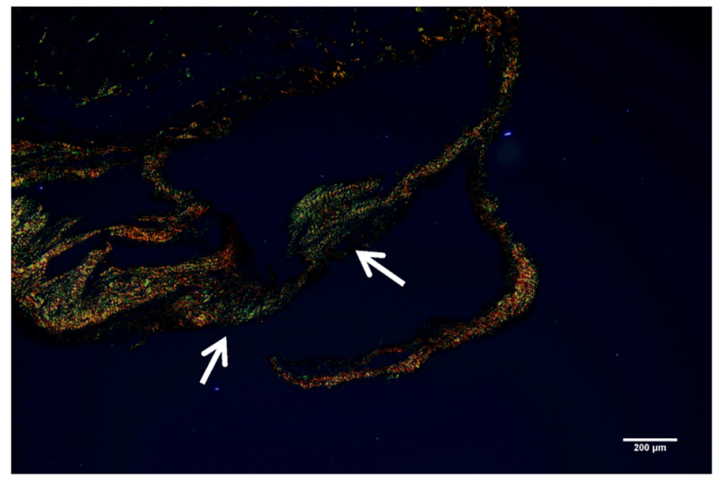

$\mathrm{RHD}$

$\mathrm{D}$

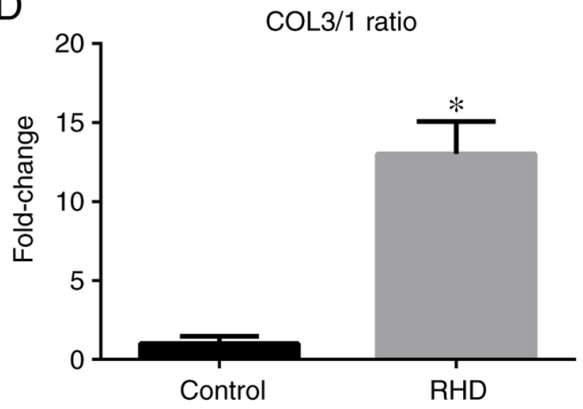

Figure 1. H\&E and Sirius red staining of valve tissues. (A) H\&E staining. RHD-induced valvular damage was observed in the RHD group. Magnification, $\mathrm{x} 400$. Scale bar $=50 \mu \mathrm{m}$. Arrows represent inflammatory cells and inflammatory exudate. (B) Sirius red staining. RHD-induced fibrosis was observed in the RHD group. Magnification, $x 100$. Scale bar=200 $\mu \mathrm{m}$. Arrows represent COL3 (green fibers with weak birefringence). (C) Inflammatory cell density of the valves in RHD group was significantly higher compared with the control group. (D) COL3/1 ratio valves in the RHD group were higher compared with the control group. The data are presented as the means \pm standard deviation. ${ }^{*} \mathrm{P}<0.05$ vs. the control group. H\&E, hematoxylin and eosin staining; RHD, rheumatic heart disease; H\&E, hematoxylin and eosin; RHD, rheumatic heart disease; COL3, collagen fiber type 3; COL1, collagen fiber type 1.

\section{Discussion}

RHD is an autoimmune disease caused by rheumatic fever following group A hemolytic streptococcal infection and threatens the health of a large number of patients every year (34). RHD remains a global health issue, especially in developing countries, being responsible for the deaths of 250,000 young people worldwide each year, with $>15$ million people exhibiting evidence of rheumatic heart disease (35). The results of previous studies have shown that acute valvulitis is present in the valves of RHD model rats and that valve damage in these animals is associated with Th17 cell-related cytokines (27,36,37). However, the exact pathological mechanism of RHD-induced cardiac valve damage remains to be elucidated.

Mitral valve disease is the most common condition in RHD, while isolated aortic valve disease occurs in $\sim 2 \%$ of patients with RHD in India (38). The mitral valve is formed by two layers of endothelial cells that tightly cover connective tissue and endothelial damage is directly associated with valvular disease (3).

The EndMT is the process by which endothelial cells lose the endothelial phenotype and acquire the characteristic phenotype of mesenchymal cells, a process first discovered by Elizabeth Hay in a study of chicken embryos (39). The transformation of endothelial cells occurs throughout the life cycle, from the development of heart valves during the embryonic stage to pathological changes in valvular disease after birth (40). The EndMT serves a key role in the occurrence and development of various cardiovascular diseases. As early as 2003, Kuwahara et al (41) observed that the TGF- $\beta$ signaling pathway is important in cardiac fibrosis and diastolic heart failure in rats and that altering the activity of this pathway inhibits the 
A
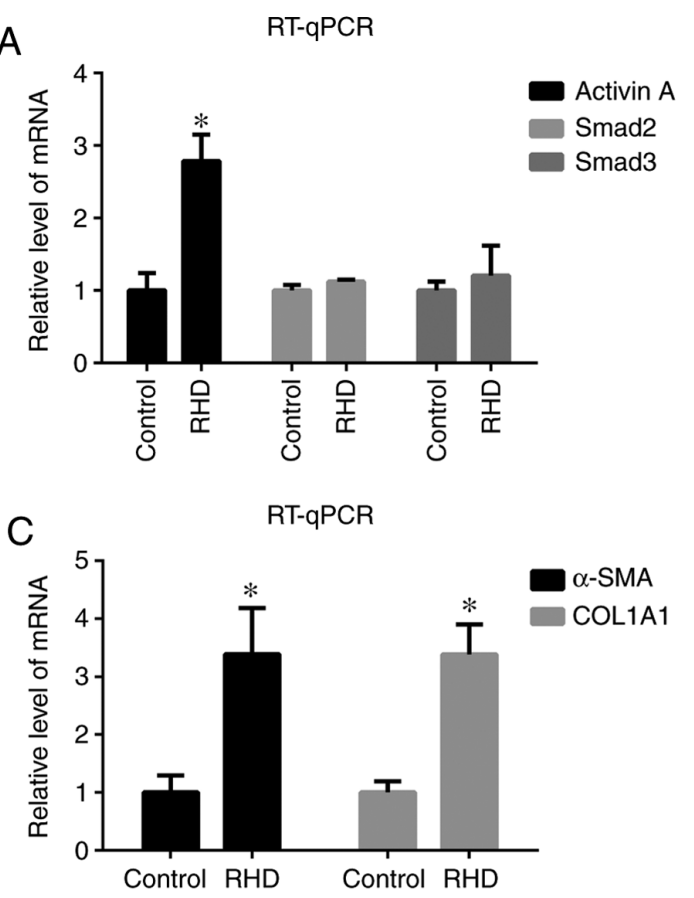

B

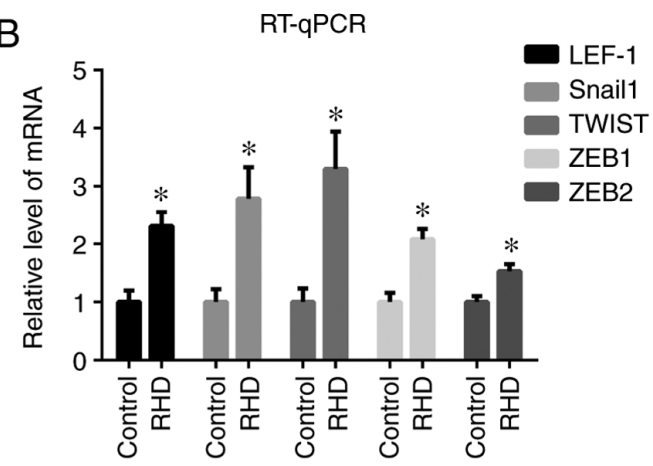

D

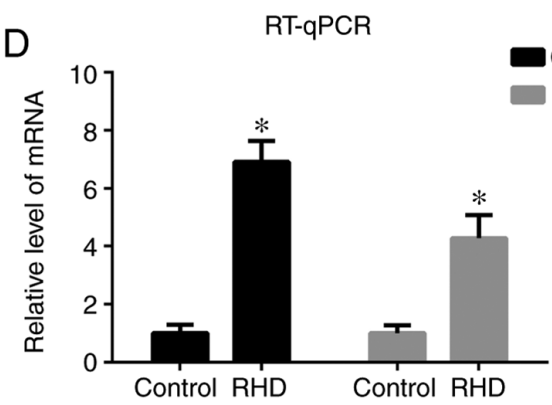

COL3A1

FSP1

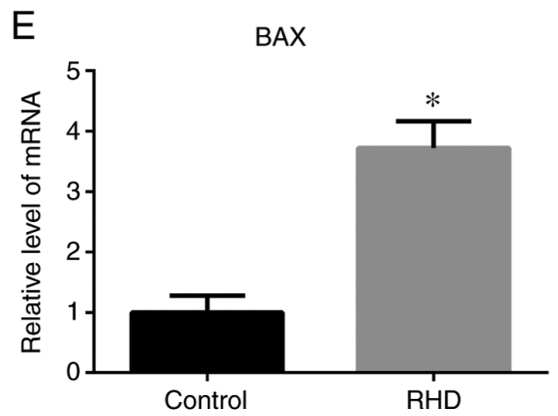

Figure 2. RT-qPCR results for the relative expression of (A) activin A, Smad2 and Smad3 in the two groups, (B) LEF-1, Snail1, TWIST, ZEB1 and ZEB2, (C) $\alpha$-SMA and COL1A1, (D) COL3A1 and FSP1 and (E) BAX in the two groups. The results show that expression of activin A, LEF-1, Snail1, TWIST, ZEB1, ZEB2, $\alpha$-SMA, COL1A1, COL3A1, FSP1 and BAX was increased in the RHD group. Data are presented as the means \pm standard deviation. "P $<0.05$ vs. respective control group. RT-qPCR, reverse transcription-quantitative PCR; LEF-1, lymphoid enhancer factor-1; ZEB, zinc finger E-box binding homeobox; $\alpha$-SMA, $\alpha$ smooth muscle actin; COL1A1, type I collagen; COL3A1, collagen type III $\alpha 1$ chain; FSP1, fibroblast-specific protein 1; RHD, rheumatic heart disease.

progression of cardiac fibrosis. Recent studies have shown that the EndMT is associated with heart failure (20,42-44) and is also crucial in cardiac fibrosis following myocardial infarction (45). Cardiac function can be improved by inhibiting EndMT (46). Multiple studies have found that attenuated EndMT can reduce cardiac fibrosis $(11,20,47-51)$. EndMT can also cause vascular endothelial dysfunction and serves an important role in the process of atherosclerosis $(52,53)$ and pulmonary fibrosis (54-56). The results of a study by Zhong et al (57) further elucidated the mechanism by which Wnt1/ $\beta$ activates the EndMT in response to valve stiffening and promotes myofibrogenesis. Wylie-Sears et al (58), by isolating and culturing sheep mitral valve endothelial cells, reported that mitral valve endothelial cells possess the potential to differentiate into mesenchymal cells. Therefore, EndMT is widely involved in the pathological process related to endothelial cells. The mitral valve is formed by two layers of endothelial cells (3) and its pathology is probably related to EndMT.

Mitral valve disease is closely associated with mitral endothelial dysfunction. In patients with mitral valve disease, the levels of microparticles in endothelial cells are significantly increased compared with those observed in normal individuals and the normal function of endothelial cells is impaired (59). A previous study observed the EndMT and activated myofibroblast-like interstitial cells in mitral endothelial tissue of ischemic mitral regurgitation in sheep, which showed that endothelial disease of the mitral valve is related to EndMT (60). During the EndMT, mitral valve endothelial cells secrete a bone-protecting protein that is positively correlated with the severity of mitral valve prolapse (9). In 2016, Bischoff et al (61) reported that the EndMT is the pathological basis of leaflet fibrosis and leaflet dysfunction in the ischemic mitral regurgitation model in Dorset hybrid sheep. These findings demonstrated that endothelial cell dysfunction caused by the EndMT is involved in the pathological process of mitral valve prolapse and ischemic mitral valve reflux. Based on these results, it was hypothesized that the EndMT may be involved in the pathological process of RHD-induced mitral valve disease.

A number of studies have identified multiple signaling pathways involved in regulating the EndMT, among which 
A
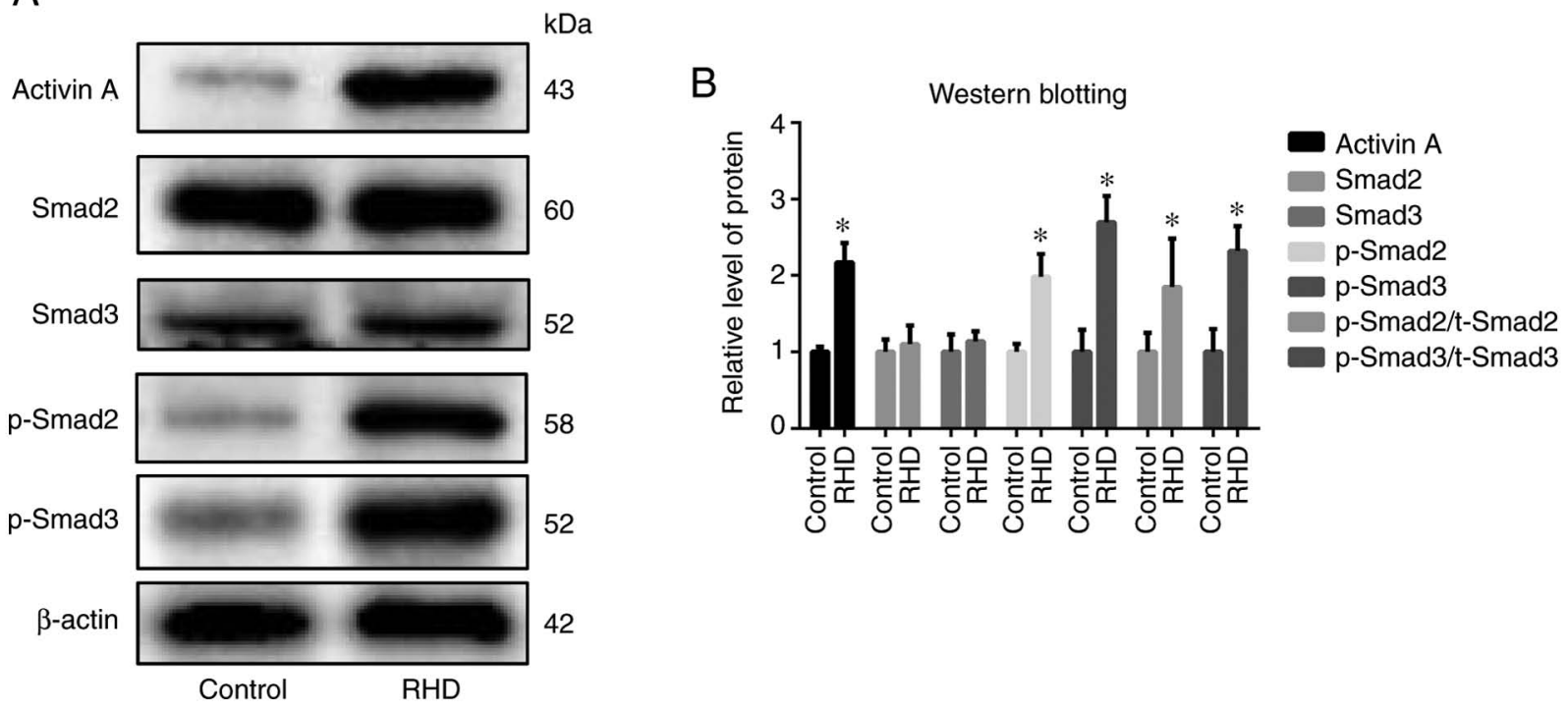

Figure 3. Western blot analysis for (A) activin A, Smad2, Smad3, p-Smad2 and p-Smad3 levels in the two groups and (B) quantified protein levels. Protein levels of activin A, p-Smad 2 and p-Smad3 were increased in RHD group. Data are presented as the means \pm standard deviation. ${ }^{*} \mathrm{P}<0.05$ vs. respective control. p-, phosphorylated; RHD, rheumatic heart disease.

A

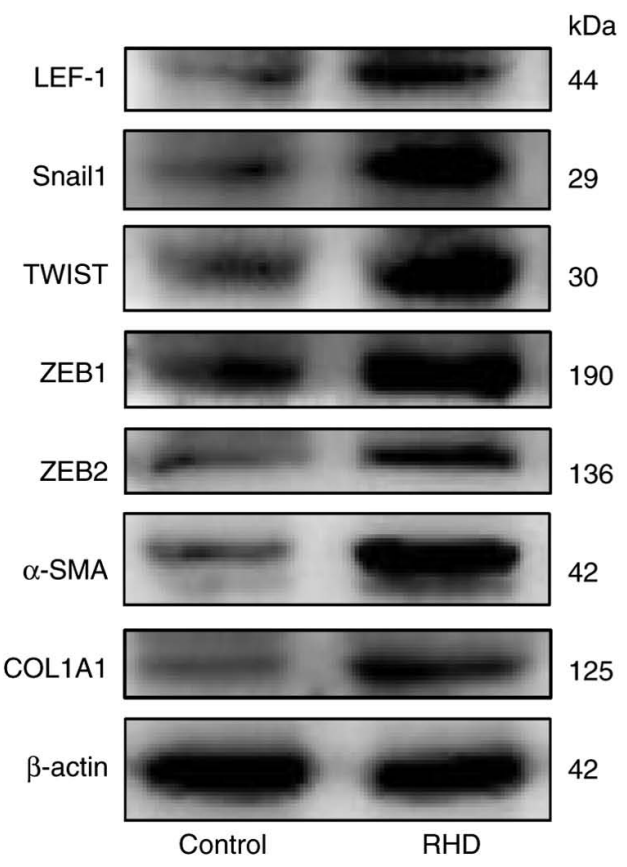

B
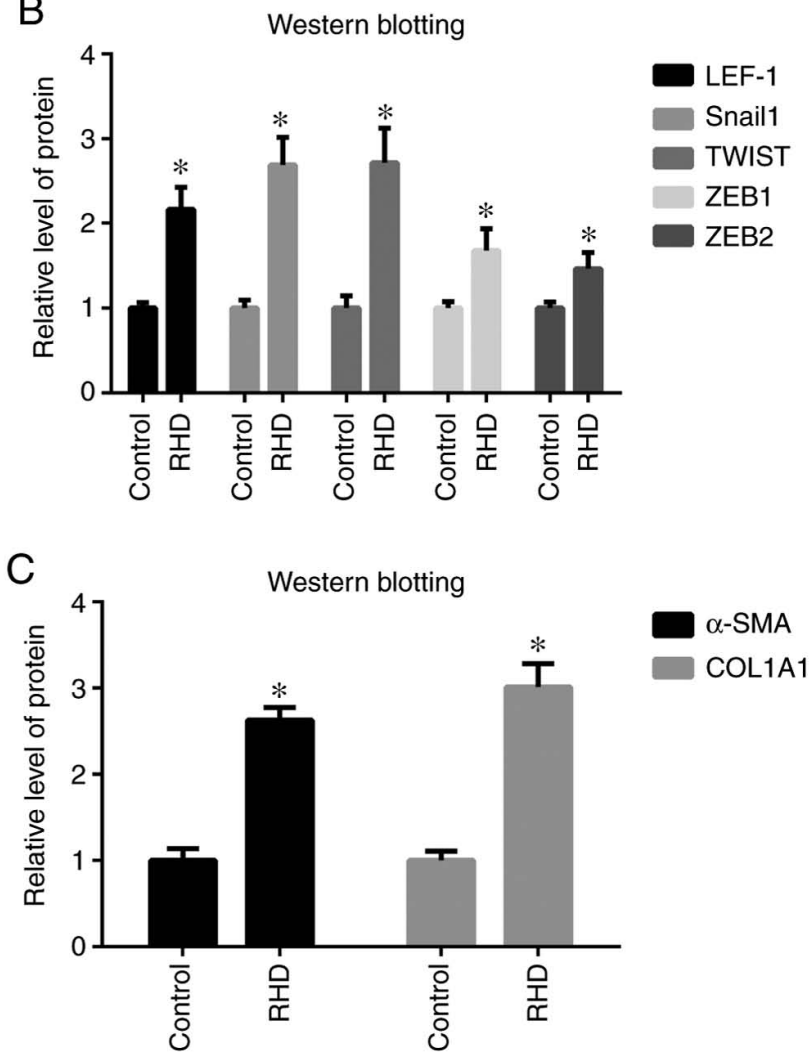

Figure 4. Western blot analysis of (A) LEF-1, Snail1, TWIST, ZEB1, ZEB2, $\alpha$-SMA and COL1A1 levels in the two groups and (B) quantified protein expression levels. (C) Relative protein expression of $\alpha$-SMA and COL1A1. Protein expression of LEF-1, Snail1, TWIST, ZEB1, ZEB2, $\alpha$-SMA and COL1A1 was increased in RHD group. The data are presented as the means \pm standard deviation. " $\mathrm{P}<0.05$ vs. respective control. LEF-1, lymphoid enhancer factor- $1 ;$ ZEB, zinc finger E-box binding homeobox; $\alpha$-SMA, $\alpha$ smooth muscle actin; COL1A1, type I collagen; RHD, rheumatic heart disease.

the cardiac-specific signaling pathways include the TGF- $\beta$, BMP, Notch, Wnt and Gata4 signaling pathways (15,62-66). The TGF- $\beta$ signaling pathway induces the EndMT through a variety of intracellular messengers (67). The TGF- $\beta$ family includes at least 30 ligand molecules, which can be divided into two subfamilies, TGF- $\beta$ /activin/Nodal and BMP/GDF/MIS, based on the similarities between the molecules and the specific downstream signaling pathways that they activate (16). 

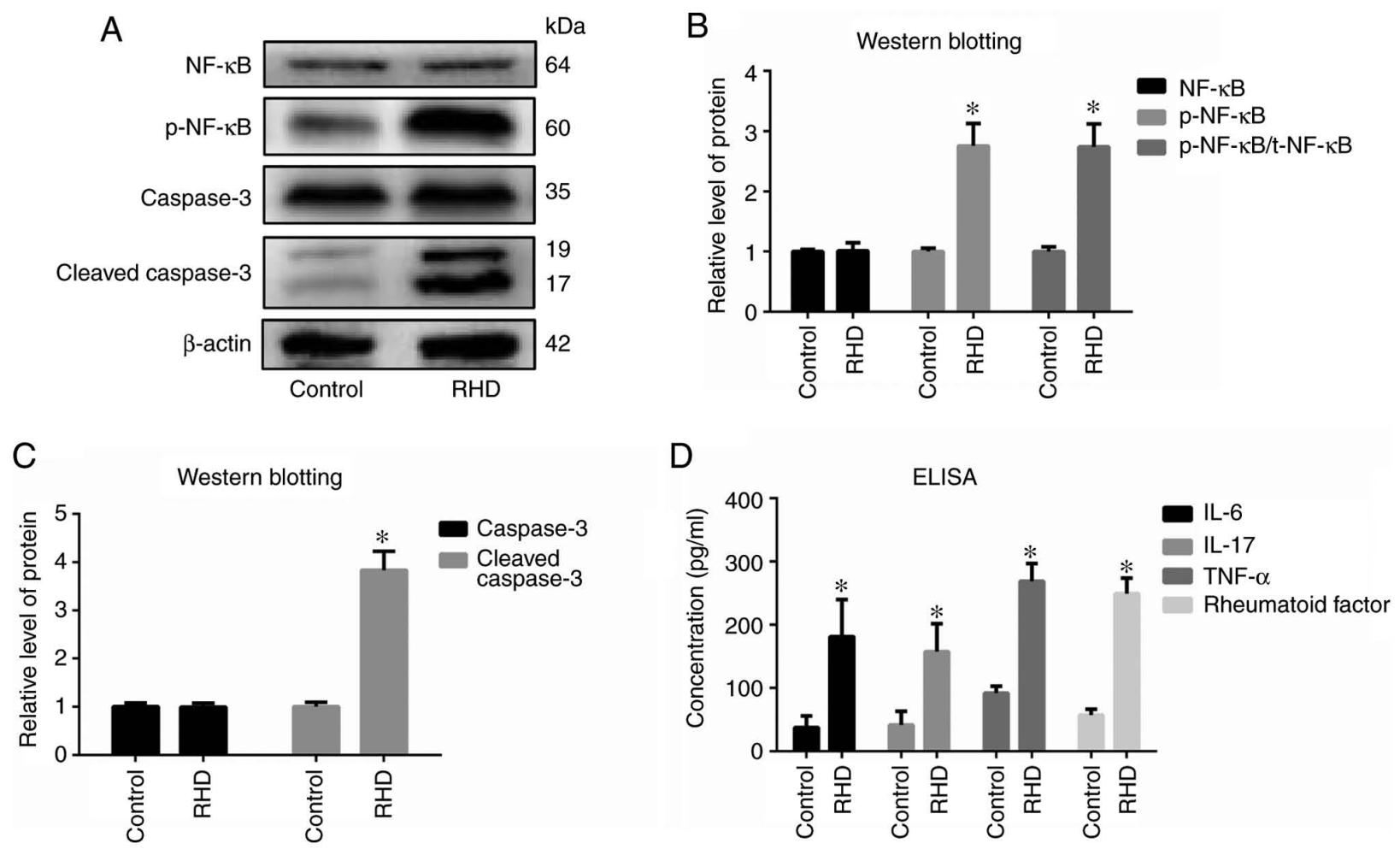

Figure 5. Analysis of valvular inflammation markers, apoptosis-related markers, cytokines and rheumatoid factor. (A) Western blot analysis of NF- $\mathrm{B}$, p-NF- $\kappa \mathrm{B}$, caspase-3 and cleaved caspase-3 levels in the two groups and (B) quantified relative protein expression levels. (C) Relative protein expression of caspase-3 and cleaved caspase-3. (D) Concentrations of IL-6, IL-17, TNF- $\alpha$ and rheumatoid factor in serum detected using ELISA. Results show that the ratio of $\mathrm{p}-\mathrm{NF}-\mathrm{\kappa B} / \mathrm{t}-\mathrm{NF}-\mathrm{\kappa B}$ and the expression of p-NF- $\mathrm{BB}$, cleaved caspase-3, IL-6, IL-17, TNF- $\alpha$ and rheumatoid factor was increased in the RHD group. Data are presented as the means \pm standard deviation. ${ }^{*} \mathrm{P}<0.05$ vs. respective control. $\mathrm{p}$-, phosphorylated; RHD, rheumatic heart disease.

Activin, a member of the TGF- $\beta$ subfamily, has the same expression pattern as that of TGF- $\beta$ during TGF- $\beta$-induced signal transduction. Activin first binds activinRII to form a complex on the cell membrane that subsequently binds activinRI to form an activinRII-activin-activinRI complex and, following phosphorylation, this complex forms docking sites that bind the transcription factors Smad2 and Smad3 (16-18). The Smad2/3 complex is phosphorylated and forms a complex with SMAD4 (68-70). Once inside the nucleus, the Smad complex induces the transcription of key genes associated with the EndMT (such as snaill, smad2 and smad3) and directly regulates a number of transcription factors that induce the EndMT $(14,71)$. A number of studies have demonstrated that EndMT is regulated by Smad2/3. A recent study reported that using forkhead box M1 to increase the expression of Smad2/3 can promote the EndMT (72). EndMT is involved in the cardiac fibrosis of diabetic cardiomyopathy and is regulated by the $\operatorname{Smad} 2 / 3$ signaling pathway (51). Calcitriol can attenuate TGF- $\beta$-induced EndMT by inhibiting the Smad2 pathway (42). Sirtuin 1 activated by resveratrol can regulate EndMT to alleviate isoproterenol-induced cardiac fibrosis by regulating the TGF- $\beta / \operatorname{Smad} 2 / 3$ pathway (19). Activated TGF- $\beta /$ Smad signaling, elevated levels of EndMT and fibrosis were also observed in the hearts of diabetic mice and cathelicidin-related antimicrobial peptide can inhibit EndMT and cardiac fibrosis though TGF- $\beta /$ Smad signaling pathway (73). Twist1 overexpression and Smad2 phosphorylation can induce EndMT in human pulmonary artery endothelial cells (74). MicroRNA-142-3p can attenuate
EndMT in human aortic endothelial cells induced by high glucose by blocking the TGF- $\beta 1 /$ Smad signaling pathway (75). Therefore, the EndMT has a close association with the Smad2/3 signaling pathway and, since the EndMT may be involved in the pathological process of RHD-induced mitral valve disease, it was hypothesized that the activin/Smad2 and 3 signaling pathway is activated during RHD-induced valve damage.

The results of the present study supported this hypothesis. The results of H\&E staining, Sirius red staining, ELISA, apoptosis-related (BAX and cleaved caspase-3), valvular inflammation (NF- $\mathrm{BB}$ and TNF- $\alpha$ ) and fibrosis molecular (COL3A1 and FSP1) marker levels showed that valve damage was caused by RHD, consistent with previous results obtained using RHD model rats $(27,36,37)$. RT-qPCR, western blotting and ELISA results showed that the levels of activin/Smad2 and 3 signaling pathway-related factors (activin A, p-Smad2 and $\mathrm{p}-\mathrm{Smad} 3$ ) in the RHD group were significantly higher compared with those observed in the control group, suggesting that the activin/Smad 2 and 3 signaling pathway was activated during the development of RHD-induced cardiac valve damage. Furthermore, RT-qPCR and western blotting results revealed significantly higher expression of EndMT-related factors (LEF-1, Snail1, TWIST, ZEB1, ZEB2, $\alpha$-SMA and COL1A1) in the RHD group compared with the control group, suggesting that the EndMT is involved in RHD-induced cardiac valve damage. The main purpose of the present study on activin/Smad2 and 3 signaling pathway was to verify whether this pathway was activated in RHD, so the main indicators detected were activin, Smad2, Smad3, p-Smad2 
and $\mathrm{p}-\mathrm{Smad} 3$. Therefore, other upstream and downstream signaling molecules in the activin/Smad 2 and 3 signaling pathway were not tested in the present study and should be investigated in future research.

The present study possessed some limitations. As the results were obtained using an RHD rat model, the findings may not accurately reflect the pathogenesis of RHD in human patients. Thus, additional studies are required to validate the present findings in an animal model that mimics human biology more closely. Relevant cellular experiments are also needed to further corroborate the results such as using genetic technology to intervene in the expression of activin/Smad2 and 3 signaling pathway and then detecting the expression of downstream molecules to further explore the regulatory mechanism of activin/Smad2 and 3 signaling pathway, as are studies on the specific mechanism by which the activin/Smad2 and 3 signaling pathway and the EndMT are involved in RHD-induced cardiac valve damage. In addition, further clinical/physiological examinations could improve the establishment of the RHD rat model, which should be improved in future experiments.

RHD is a major disease worldwide that threatens the health of 300,000 individuals worldwide every year (1). However, the pathogenesis of RHD remains poorly understood. Based on the results of previous research on the EndMT, it was hypothesized that the EndMT is involved in valvular damage due to RHD. Due to the association between the activin/Smad2 and 3 signaling pathway and the EndMT, it was hypothesized that this pathway is activated during the process of valve damage caused by RHD. Therefore, the goal of the present study was to verify the hypothesis by establishing an RHD rat model and evaluating the differences in expression of activin/Smad 2 and 3 signaling pathway-related factors and EndMT-related factors between the RHD and control groups. The results suggested that the activin/Smad 2 and 3 signaling pathway was activated during the development of valvular damage caused by RHD and that the EndMT is involved in RHD-induced cardiac valve damage. Our findings can help explore the pathogenesis of RHD and further our understanding to inform improved treatments of RHD.

\section{Acknowledgements}

Not applicable.

\section{Funding}

The present study was supported by the National Natural Science Foundation of China (grant no. 81960082), the Guangxi Key Laboratory Base of Precision Medicine in Cardio-cerebrovascular Disease Control and Prevention (grant no. 17-259-85), the Guangxi Clinical Research Center for Cardio-cerebrovascular Diseases (grant no. AD17129014) and the Guangxi Medical High-level Backbone Talents '139' Program (grant no. G201901006).

\section{Availability of data and materials}

All data generated or analyzed during this study are included in this published article.

\section{Authors' contributions}

$\mathrm{ZZ}$ and FH conceived and designed the study. SX, AC and $\mathrm{XW}$ participated in the experimental design. SX, AC and YW performed the experiments. SX, AC and CL analyzed the data. SX wrote the manuscript and all authors contributed to the final manuscript. All authors read and approved the final manuscript.

\section{Ethics approval and consent to participate}

Protocols involving animals were approved by The Medical Ethics Committee of the First Affiliated Hospital of Guangxi Medical University (Nanning, China; approval no. 2019-KY-E-053).

\section{Patient consent for publication}

Not applicable.

\section{Competing interests}

The authors declare that they have no competing interests.

\section{References}

1. Watkins DA, Johnson CO, Colquhoun SM, Karthikeyan G, Beaton A, Bukhman G, Forouzanfar MH, Longenecker CT Mayosi BM, Mensah GA, et al: Global, regional, and national burden of rheumatic heart disease, 1990-2015. N Engl J Med 377: 713-722, 2017.

2. Remenyi B, Carapetis J, Wyber R, Taubert K and Mayosi BM; World Heart Federation: Position statement of the World Heart Federation on the prevention and control of rheumatic heart disease. Nat Rev Cardiol 10: 284-292, 2013.

3. Remenyi B, ElGuindy A, Smith SC Jr, Yacoub M and Holmes DR Jr: Valvular aspects of rheumatic heart disease. Lancet 387: 1335-1346, 2016.

4. Naghavi M, Abajobir AA, Abbafati C, Abbas KM, Abd-Allah F, Abera SF, Aboyans V, Adetokunboh O, Afshin A, Agrawal A, et al; GBD 2016 Causes of Death Collaborators: Global, regional, and national age-sex specific mortality for 264 causes of death, 1980-2016: A systematic analysis for the Global Burden of Disease Study 2016. Lancet 390: 1151-1210, 2017.

5. Roth GA, Abate D, Abate KH, Abay SM, Abbafati C, Abbasi N Abbastabar H, Abd-Allah F, Abdela J, Abdelalim A, et al; GBD 2017 Causes of Death Collaborators: Global, regional, and national age-sex-specific mortality for 282 causes of death in 195 countries and territories, 1980-2017: A systematic analysis for the Global Burden of Disease Study 2017. Lancet 392: 1736-1788, 2018.

6. Salem A, Abdelgawad AME and Elshemy A: Early and midterm outcomes of rheumatic mitral valve repair. Heart Surg Forum 21: E352-E358, 2018.

7. Elsayed AAA, Abdelaal KM, Abdelghaffar AMM Mohamed EEH, Mahran TMA, Ahmed MSM, Ibrahim AM and Mansour AA: Poor outcome of surgical management of acute malfunctioning mechanical mitral valve during pregnancy. Should centers with limited resources find different options? Heart Surg Forum 22: E405-E410, 2019.

8. Pagnozzi LA and Butcher JT: Mechanotransduction mechanisms in mitral valve physiology and disease pathogenesis. Front Cardiovasc Med 4: 83, 2017.

9. Songia P, Branchetti E, Parolari A, Myasoedova V, Ferrari G, Alamanni F, Tremoli E and Poggio P: Mitral valve endothelial cells secrete osteoprotegerin during endothelial mesenchymal transition. J Mol Cell Cardiol 98: 48-57, 2016.

10. Hong L, Du X, Li W, Mao Y, Sun L and Li X: EndMT: A promising and controversial field. Eur J Cell Biol 97: 493-500, 2018. 
11. Wei WY, Zhang N, Li LL, Ma ZG, Xu M, Yuan YP, Deng W and Tang QZ: Pioglitazone alleviates cardiac fibrosis and inhibits endothelial to mesenchymal transition induced by pressure overload. Cell Physiol Biochem 45: 26-36, 2018.

12. Xiao M,Zhang M, Bie M, Wang X, Guo J and Xiao H: Galectin-3 induces atrial fibrosis by activating the TGF- $\beta 1 / \mathrm{Smad}$ pathway in patients with atrial fibrillation. Cardiology 145: 446-455, 2020.

13. Thuault S, Tan EJ, Peinado H, Cano A, Heldin $\mathrm{CH}$ and Moustakas A: HMGA2 and Smads co-regulate SNAIL1 expression during induction of epithelial-to-mesenchymal transition. J Biol Chem 283: 33437-33446, 2008.

14. Vincent T, Neve EP, Johnson JR, Kukalev A, Rojo F, Albanell J, Pietras K, Virtanen I, Philipson L, Leopold PL, et al: A SNAIL1-SMAD3/4 transcriptional repressor complex promotes TGF-beta mediated epithelial-mesenchymal transition. Nat Cell Biol 11: 943-950, 2009

15. Kovacic JC, Mercader N, Torres M, Boehm M and Fuster V: Epithelial-to-mesenchymal and endothelial-to-mesenchymal transition: From cardiovascular development to disease. Circulation 125: 1795-1808, 2012.

16. Massagué J: How cells read TGF-beta signals. Nat Rev Mol Cell Biol 1: 169-178, 2000

17. Itoh S, Itoh F, Goumans MJ and Ten Dijke P: Signaling of transforming growth factor-beta family members through Smad proteins. Eur J Biochem 267: 6954-6967, 2000

18. Moustakas A, Souchelnytskyi S and Heldin CH: Smad regulation in TGF-beta signal transduction. J Cell Sci 114: 4359-4369, 2001

19. Liu ZH, Zhang Y, Wang X, Fan XF, Zhang Y, Li X, Gong YS and Han LP: SIRT1 activation attenuates cardiac fibrosis by endothelial-to-mesenchymal transition. Biomed Pharmacother 118 109227, 2019.

20. Xu L, Fu M, Chen D, Han W, Ostrowski MC, Grossfeld P, Gao P and Ye M: Endothelial-specific deletion of Ets-1 attenuates Angiotensin II-induced cardiac fibrosis via suppression of endothelial-to-mesenchymal transition. BMB Rep 52: 595-600, 2019.

21. Maleki S, Cottrill KA, Poujade FA, Bhattachariya A, Bergman O, Gådin JR, Simon N, Lundströmer K, Franco-Cereceda A Björck HM, et al: The mir-200 family regulates key pathogenic events in ascending aortas of individuals with bicuspid aortic valves. J Intern Med 285: 102-114, 2019.

22. Zhang B, Niu W, Dong HY, Liu M-L, Luo Y and Li ZC: Hypoxia induces endothelial mesenchymal transition in pulmonary vascular remodeling. Int J Mol Med 42: 270-278, 2018.

23. Fang S, Guo H, Cheng Y, Zhou Z, Zhang W, Han B, Luo W, Wang J, Xie W and Chao J: circHECTD1 promotes the silica-induced pulmonary endothelial-mesenchymal transition via HECTD1. Cell Death Dis 9: 396-396, 2018.

24. Gorton D, Govan B, Olive C and Ketheesan N: B- and T-cell responses in group a streptococcus M-protein- or Peptide-induced experimental carditis. Infect Immun 77: 2177-2183, 2009.

25. Gorton D, Blyth S, Gorton JG, Govan B and Ketheesan N: An alternative technique for the induction of autoimmune valvulitis in a rat model of rheumatic heart disease. J Immunol Methods 355: 80-85, 2010.

26. Lymbury RS, Olive C, Powell KA, Good MF, Hirst RG, LaBrooy JT and Ketheesan N: Induction of autoimmune valvulitis in Lewis rats following immunization with peptides from the conserved region of group A streptococcal M protein. J Autoimmun 20: 211-217, 2003

27. Chen A, Wen J, Lu C, Lin B, Xian S, Huang F, Wu Y and Zeng Z: Inhibition of miR-155-5p attenuates the valvular damage induced by rheumatic heart disease. Int J Mol Med 45: 429-440, 2020.

28. Zhan Q, Zeng Q, Song R, Zhai Y, Xu D, Fullerton DA, Dinarello CA and Meng X: IL-37 suppresses MyD88-mediated inflammatory responses in human aortic valve interstitial cells. Mol Med 23: 83-91, 2017.

29. Blake RR, Markby GR, Culshaw GJ, Martinez-Pereira Y, Lu CC and Corcoran BM: Survival of activated myofibroblasts in canine myxomatous mitral valve disease and the role of apoptosis. Res Vet Sci 128: 99-106, 2020.

30. Pande S, Tewari P, Agarwal SK, Agarwal V, Agrawal V, Chagtoo M, Majumdar G and Tewari S: Evidence of apoptosis in right ventricular dysfunction in rheumatic mitral valve stenosis. Indian J Med Res 144: 718-724, 2016.

31. Trihia H, Siatra H, Gklisty H, Diamantopoulos $P$, Arapantoni-Dadiotis $\mathrm{P}$ and Kalogerakos K: Lymphoepithelioma-like carcinoma of the breast: Cytological and histological features and review of the literature. Acta Cytol 56: 85-91, 2012.
32. Cardiff RD, Miller CH and Munn RJ: Manual hematoxylin and eosin staining of mouse tissue sections. Cold Spring Harb Protoc 2014: 655-658, 2014.

33. Purushothaman KR, Purushothaman M, Turnbull IC, Adams DH, Anyanwu A, Krishnan P, Kini A, Sharma SK, O'Connor WN and Moreno PR: Association of altered collagen content and lysyl oxidase expression in degenerative mitral valve disease. Cardiovasc Pathol 29: 11-18, 2017.

34. Sharma N and Toor D: Interleukin-10: Role in increasing susceptibility and pathogenesis of rheumatic fever/rheumatic heart disease. Cytokine 90: 169-176, 2017.

35. Dass C and Kanmanthareddy A: Rheumatic heart disease. StatPearls [Internet]. StatPearls Publishing, Treasure Island, FL, 2020.

36. Wu XD, Zeng ZY, Gong DP, Wen JL and Huang F: Potential involvement of S1PR1/STAT3 signaling pathway in cardiac valve damage due to rheumatic heart disease. Biotech Histochem 94: 398-403, 2019

37. Wen Y, Zeng Z, Gui C, Li L, Li W: Changes in the expression of Th17 cell-associated cytokines in the development of rheumatic heart disease. Cardiovasc Pathol 24: 382-387, 2015.

38. Chockalingam A, Gnanavelu G, Elangovan $S$ and Chockalingam V: Clinical spectrum of chronic rheumatic heart disease in India. J Heart Valve Dis 12: 577-581, 2003.

39. Trelstad RL, Hay ED and Revel JD: Cell contact during early morphogenesis in the chick embryo. Dev Biol 16: 78-106, 1967.

40. Bischoff J: Endothelial-to-mesenchymal transition. Circ Res 124: $1163-1165,2019$.

41. Kuwahara F, Kai H, Tokuda K, Kai M, Takeshita A, Egashira K and Imaizumi T: Transforming growth factor-beta function blocking prevents myocardial fibrosis and diastolic dysfunction in pressure-overloaded rats. Circulation 106: 130-135, 2002

42. Tsai TH, Lin CJ, Hang CL and Chen WY: Calcitriol attenuates doxorubicin-induced cardiac dysfunction and inhibits endothelial-to-mesenchymal transition in mice. Cells 8: 8, 2019.

43. Zheng G, Cai J, Chen X, Chen L, Ge W, Zhou X and Zhou H: Relaxin ameliorates renal fibrosis and expression of endothelial cell transition markers in rats of isoproterenol-induced heart failure. Biol Pharm Bull 40: 960-966, 2017.

44. Mai JT, Hu QS, Xie Y, Su SC, Qiu Q, Yuan WL, Yang Y, Song YW, Chen YX and Wang JF: Dyssynchronous pacing triggers endothelial-mesenchymal transition through heterogeneity of mechanical stretch in a canine model. Circ J 79: 201-209, 2015.

45. Chen J, Jia J, Ma L, Li B, Qin Q, Qian J and Ge J: Nur77 deficiency exacerbates cardiac fibrosis after myocardial infarction by promoting endothelial-to-mesenchymal transition. J Cell Physiol: Jun 15, 2020 (Epub ahead of print).

46. Wu Y, Xu M, Bao H and Zhang JH: Sitagliptin inhibits EndMT in vitro and improves cardiac function of diabetic rats through the SDF-1 $\alpha /$ PKA pathway. Eur Rev Med Pharmacol Sci 23: 841-848, 2019.

47. Song S, Liu L, Yu Y, Zhang R, Li Y, Cao W, Xiao Y, Fang G, Li Z, Wang X, et al: Inhibition of BRD4 attenuates transverse aortic constriction- and TGF- $\beta$-induced endothelial-mesenchymal transition and cardiac fibrosis. J Mol Cell Cardiol 127: 83-96, 2019.

48. Liu Y, Gao L, Zhao X, Guo S, Liu Y, Li R, Liang C, Li L, Dong J, Li L, et al: Saikosaponin A protects from pressure overload-induced cardiac fibrosis via inhibiting fibroblast activation or endothelial cell EndMT. Int J Biol Sci 14: 1923-1934, 2018.

49. Lai YJ, Chen IC, Li HH and Huang CC: EP4 Agonist L-902,688 suppresses EndMT and attenuates right ventricular cardiac fibrosis in experimental pulmonary arterial hypertension. Int $\mathrm{J}$ Mol Sci 19: 19, 2018

50. Wang Z, Wang Z, Gao L, Xiao L, Yao R, Du B, Li Y, Wu L, Liang C, Huang Z, et al: miR-222 inhibits cardiac fibrosis in diabetic mice heart via regulating $\mathrm{Wnt} / \beta$-catenin-mediated endothelium to mesenchymal transition. J Cell Physiol 235: 2149-2160, 2020

51. Wang B, Wu Y, Ge Z, Zhang X, Yan Y and Xie Y: NLRC5 deficiency ameliorates cardiac fibrosis in diabetic cardiomyopathy by regulating EndMT through Smad2/3 signaling pathway. Biochem Biophys Res Commun 528: 545-553, 2020.

52. Souilhol C, Harmsen MC, Evans PC and Krenning G: Endothelial-mesenchymal transition in atherosclerosis. Cardiovasc Res 114: 565-577, 2018.

53. Hao YM, Yuan HQ, Ren Z, Qu SL, Liu LS, Wei DH, Yin K, Fu M and Jiang ZS: Endothelial to mesenchymal transition in atherosclerotic vascular remodeling. Clin Chim Acta 490: 34-38, 2019. 
54. Song S, Ji Y, Zhang G, Zhang X,Li B, Li D and Jiang W: Protective effect of atazanavir sulphate against pulmonary fibrosis in vivo and in vitro. Basic Clin Pharmacol Toxicol 122: 199-207, 2018.

55. Gaikwad AV, Eapen MS, McAlinden KD, Chia C, Larby J, Myers S, Dey S, Haug G, Markos J, Glanville AR, et al: Endothelial to mesenchymal transition (EndMT) and vascular remodeling in pulmonary hypertension and idiopathic pulmonary fibrosis. Expert Rev Respir Med 14: 1027-1043, 2020.

56. Yu J, Deng Y and Han M: Blocking protein phosphatase $2 \mathrm{~A}$ with a peptide protects mice against bleomycin-induced pulmonary fibrosis. Exp Lung Res 46: 234-242, 2020.

57. Zhong A, Mirzaei Z and Simmons CA: The roles of matrix stiffness and $\beta$-catenin signaling in endothelial-to-mesenchymal transition of aortic valve endothelial cells. Cardiovasc Eng Technol 9: 158-167, 2018

58. Wylie-Sears J, Aikawa E, Levine RA, Yang JH and Bischoff J: Mitral valve endothelial cells with osteogenic differentiation potential. Arterioscler Thromb Vasc Biol 31: 598-607, 2011.

59. Ci HB, Ou ZJ, Chang FJ, Liu DH, He GW, Xu Z, Yuan HY, Wang ZP, Zhang X and Ou JS: Endothelial microparticles increase in mitral valve disease and impair mitral valve endothelial function. Am J Physiol Endocrinol Metab 304: E695-E702, 2013

60. Shapero K, Wylie-Sears J, Levine RA, Mayer JE Jr and Bischoff J: Reciprocal interactions between mitral valve endothelial and interstitial cells reduce endothelial-to-mesenchyma transition and myofibroblastic activation. J Mol Cell Cardiol 80: 175-185, 2015.

61. Bischoff J, Casanovas G, Wylie-Sears J, Kim DH, Bartko PE, Guerrero JL, Dal-Bianco JP, Beaudoin J, Garcia ML, Sullivan SM, et al: CD45 expression in mitral valve endothelial cells after myocardial infarction. Circ Res 119: 1215-1225, 2016.

62. Lan Y, Liu B, Yao H, Li F, Weng T, Yang G, Li W, Cheng X, Mao N and Yang X: Essential role of endothelial Smad4 in vascular remodeling and integrity. Mol Cell Biol 27: 7683-7692, 2007.

63. Zeisberg M, Hanai J, Sugimoto H, Mammoto T, Charytan D, Strutz F and Kalluri R: BMP-7 counteracts TGF-beta1-induced epithelial-to-mesenchymal transition and reverses chronic renal injury. Nat Med 9: 964-968, 2003.

64. Grieskamp T, Rudat C, Lüdtke TH, Norden J and Kispert A: Notch signaling regulates smooth muscle differentiation of epicardium-derived cells. Circ Res 108: 813-823, 2011.

65. Li H, Zhao Q, Chang L, Wei C, Bei H, Yin Y, Chen M, Wang H, Liang $\mathrm{J}$ and $\mathrm{Wu} \mathrm{Y}$ : LncRNA MALAT1 modulates ox-LDL induced EndMT through the Wnt/ $\beta$-catenin signaling pathway. Lipids Health Dis 18: 62, 2019.
66. Rivera-Feliciano J, Lee KH, Kong SW, Rajagopal S, Ma Q, Springer Z, Izumo S, Tabin CJ and Pu WT: Development of heart valves requires Gata4 expression in endothelial-derived cells. Development 133: 3607-3618, 2006.

67. Jiang Y, Zhou X, Hu R and Dai A: TGF- $\beta 1$-induced SMAD2/3/4 activation promotes RELM- $\beta$ transcription to modulate the endothelium-mesenchymal transition in human endothelial cells. Int J Biochem Cell Biol 105: 52-60, 2018.

68. Pickup MW, Owens Pand Moses HL: TGF- $\beta$, bone morphogenetic protein, and activin signaling and the tumor microenvironment. Cold Spring Harb Perspect Biol 9: 9, 2017.

69. Morianos I, Papadopoulou G, Semitekolou M and Xanthou G: Activin-A in the regulation of immunity in health and disease. $\mathrm{J}$ Autoimmun 104: 102314, 2019.

70. Goh BC, Singhal V, Herrera AJ, Tomlinson RE, Kim S, Faugere MC, Germain-Lee EL, Clemens TL, Lee SJ and DiGirolamo DJ: Activin receptor type 2A (ACVR2A) functions directly in osteoblasts as a negative regulator of bone mass. J Biol Chem 292: 13809-13822, 2017.

71. Peinado H, Quintanilla M and Cano A: Transforming growth factor beta-1 induces snail transcription factor in epithelial cell lines: Mechanisms for epithelial mesenchymal transitions. J Biol Chem 278: 21113-21123, 2003.

72. Song S, Zhang R, Cao W, Fang G, Yu Y, Wan Y, Wang C, Li Y and Wang Q: Foxm1 is a critical driver of TGF- $\beta$-induced EndMT in endothelial cells through Smad2/3 and binds to the Snail promoter. J Cell Physiol 234: 9052-9064, 2019.

73. Zheng X, Peng M, Li Y, Wang X, Lu W, Wang X, Shan Y, Li R, Gao L and Qiu C: Cathelicidin-related antimicrobial peptide protects against cardiac fibrosis in diabetic mice heart by regulating endothelial-mesenchymal transition. Int J Biol Sci 15: 2393-2407, 2019.

74. Mammoto T, Muyleart M, Konduri GG and Mammoto A: Twist1 in hypoxia-induced pulmonary hypertension through transforming growth factor- $\beta$-Smad signaling. Am J Respir Cell Mol Biol 58: 194-207, 2018.

75. Zhu GH, Li R, Zeng Y, Zhou $\mathrm{T}$, Xiong $\mathrm{F}$ and Zhu $\mathrm{M}$ : MicroRNA-142-3p inhibits high-glucose-induced endothelial-to-mesenchymal transition through targeting TGF- $\beta 1 /$ Smad pathway in primary human aortic endothelial cells. Int J Clin Exp Pathol 11: 1208-1217, 2018.

This work is licensed under a Creative Commons Attribution-NonCommercial-NoDerivatives 4.0 International (CC BY-NC-ND 4.0) License. 